Research Article

\title{
Displacement Monitoring during the Excavation and Support of Deep Foundation Pit in Complex Environment
}

\author{
Zhouqiang Li (iD) \\ 402 Geological Prospecting Party, Hunan Exploration Design Institute, Changsha 410004, China \\ Correspondence should be addressed to Zhouqiang Li; lizhouqiang2021@126.com
}

Received 14 April 2021; Accepted 1 June 2021; Published 7 June 2021

Academic Editor: Rihong Cao

Copyright (C) 2021 Zhouqiang Li. This is an open access article distributed under the Creative Commons Attribution License, which permits unrestricted use, distribution, and reproduction in any medium, provided the original work is properly cited.

Taking a super large deep foundation pit project as an example, the horizontal displacement of crown beam and driveway, surface settlement, axial force of anchor cable, and underground water level in the construction process of the foundation pit are dynamically monitored and analyzed. The excavation deformation rule of the deep foundation pit and the influence of excavation on surrounding buildings are analyzed. The results show that, with the excavation of the foundation pit, the crown beam and driveway of the foundation pit incline towards the direction of the pit and eventually tend to be stable. The variation of axial force of the prestressed anchor cable in the first layer of the foundation pit is basically consistent with the variation of horizontal displacement time history. The variation trend of the groundwater level at each side of the foundation pit is different but tends to be stable in a short time. In the whole monitoring period, the cumulative settlement value of each area of the foundation pit is within the controllable range, but the surface settlement of the north side of the foundation pit and a surrounding building has not reached stability, so it is suggested to extend the monitoring time of settlement in the relevant area.

\section{Introduction}

The excavation of the foundation pit is accompanied by the stress redistribution of the surrounding soil [1-4]. Under the action of earth pressure, a certain displacement will be generated towards the pit, which will affect the stability of the foundation pit and surrounding buildings. Therefore, relevant supporting measures need to be taken $[5,6]$. As a foundation pit supporting structure, the pile-anchor structure has been widely used in practical engineering [7-10]. It can make rational use of the soil's own characteristics, give full play to the mutual bonding between soil and pile-anchor structure, and have the advantages of rapid construction and low cost $[11,12]$. With the continuous development of urban construction and excavation equipment, the scale of foundation pit engineering is developing towards a larger and deeper direction [13, 14]. For the construction process of super high-rise buildings and underground garages, the excavation of the deep foundation pit has little influence on the surrounding buildings and traffic roads, so it is necessary to monitor the dynamic changes of soil indexes around the foundation pit during the excavation process [15-18]. The stability of geotechnical materials is affected by many factors [19-23]. In order to ensure the stability of the foundation pit itself and the surrounding environment as well as the pile-anchor retaining structure, dynamic monitoring is widely used as an effective means [24]. Through monitoring, the monitoring data can be compared with the design value to judge whether the previous step of construction technology and construction parameters meet the expected requirements and determine and optimize the next step of construction parameters, so as to achieve information construction [25, 26]. Zhu et al. [27] carried out physical model experiments in the laboratory based on a pit-in-pit foundation. Bennett et al. [28] present an overview of the most used nondestructive inspection (NDI) and structural health monitoring (SHM) technologies for freshwater pipes and sewers. By analyzing the 
monitoring data, we can judge whether the previous construction effect meets the requirements and guide and optimize the next step of foundation pit excavation. Based on a very large pile-anchor bracing deep foundation pit engineering as an example, the foundation pit crown beam settlement and horizontal displacement, anchor axial force, the change of underground water level in the construction period for dynamic monitoring, and the analysis of deformation of soil around the foundation pit are summarized, and the influence of excavation on surrounding buildings can provide reference for the local similar deep foundation pit engineering.

\section{Project Overview and Support Scheme}

This project is a super large underground project, the shape of which is approximately rectangular. The safety level of the foundation pit is level 1 . The excavation depth of the foundation pit is about $34 \mathrm{~m}$, and the supporting length of the foundation pit is about $1330 \mathrm{~m}$. The site consists of quaternary overburden, which includes artificial fill, alluvium and eluvium, and cretaceous bedrock, which includes silty sand and local coarse sandstone and conglomerate. The groundwater of the site is mainly quaternary pore water and bedrock fissure water. The quaternary pore water occurs in the pores of sand layer and silty clay. The sand layer is the main aquifer, and the depth of the groundwater level is $1.07 \sim 4.90 \mathrm{~m}$. There is a small amount of water leakage in bedrock fissure water, but the overall water content of bedrock is small. Combined with the engineering characteristics and site conditions, double row triple highpressure jet grouting piles are constructed around the foundation pit to strengthen the surrounding soil and cut off the seepage path of the peripheral groundwater into the foundation pit. The foundation pit support method is "double row jet grouting pile sealing curtain + artificial excavated pile + anchor cable," which is widely used in the foundation engineering $[29,30]$. The layout of foundation pit monitoring points is shown in Figure 1, where $\mathrm{C} 1-\mathrm{C} 4$ represent the driveway.

\section{Monitoring Results and Analysis}

3.1. Horizontal Displacement of Foundation Pit Crown Beam and Foundation Pit Driveway. Three reference points are set outside the influence range of building deformation, and the buried depth is $0.5 \mathrm{~m}$. The monitoring points are arranged along the perimeter of the foundation pit on the concrete roof or crown beam of the foundation pit slope. The horizontal spacing of the monitoring points is less than $20 \mathrm{~m}$, and the polar coordinate measurement method is adopted for horizontal displacement monitoring. As shown in the distribution map of the foundation pit monitoring points, the positive and negative of the horizontal displacement only represent the direction. For the convenience of analysis, the absolute value of all the monitoring data is processed. The horizontal displacement monitoring data of the short side B49, B50, B51, and B52 on the west side of the foundation pit, the long side B12, B15, and B17 on the south side of the foundation pit, and the roadway $\mathrm{C} 1, \mathrm{C} 1-1, \mathrm{C} 2, \mathrm{C} 2-1, \mathrm{C} 3$, and $\mathrm{C} 4$ of the foundation pit are taken for analysis, as shown in Figure 2. It can be seen from Figures 2(a) and 2(b) that the variation law of horizontal displacement monitoring curves of the long and short sides of the foundation pit is basically similar, and the overall trend increases with the excavation time. As shown in Figure 2(a), with the progress of soil excavation, the excavation face of the foundation pit increases continuously, and the horizontal displacement of the top of the foundation pit increases rapidly under the earth pressure outside the foundation pit. As soil excavation and prestressed anchor cable construction are carried out at the same time, the horizontal displacement of the soil around the support is limited and grows slowly. As the excavation continues, the restriction of the prestressed anchor cable on the horizontal displacement of the surrounding soil is weakened, and the pile top tends to move towards the pit. About $550 \mathrm{~d}$ after excavation, the change curve of the horizontal displacement of the pile top tends to be flat. Until the end of monitoring, the horizontal displacement of the pile top fluctuates within a controllable range. The maximum value of the horizontal displacement in the $X$ direction is the monitoring point C3, with a value of $29.3 \mathrm{~mm}$, and the maximum value of the horizontal displacement in the $Y$ direction is the monitoring point B49, with a value of $27.3 \mathrm{~mm}$, both of which do not exceed the alarm value. In addition, according to Figure 2(b), although the final cumulative values of horizontal displacements on the short edge of the foundation pit are similar, the horizontal displacements in the middle of the short edge of the foundation pit (B50 and B51) are greater than those on both sides of the short edge of the foundation pit (B49 and B52) during the excavation process. Combined with the distribution of monitoring points of the driveway and Figure 2(c), it can be seen that, in the whole monitoring cycle, with the increase of depth, the final cumulative value of horizontal displacement of the driveway increases continuously, and the curve rises at a faster rate.

3.2. Surface Settlement in Each Area of Foundation Pit. For the convenience of observation, settlement displacement observation points and horizontal displacement observation points are arranged at the same point, and round trip confluence leveling is adopted for settlement monitoring. The monitoring data of B49 and B50 on the short side of the foundation pit, B15 and B17 on the long side, $\mathrm{C} 2$ and $\mathrm{C} 3$ on the driveway of the foundation pit, and F1, F2, F3, and F4 on the surrounding buildings of the foundation pit are selected for analysis. The settlement displacement curves of the crown beam and driveway of the foundation pit are shown in Figure 3, and the settlement curves of the surrounding buildings are shown in Figure 3(b). In addition, according to the occurrence of uneven settlement on the north side of the foundation pit, additional monitoring points A1, A2, A3, and A5 were selected for analysis, and the time-history variation curve of relevant settlement was shown in 


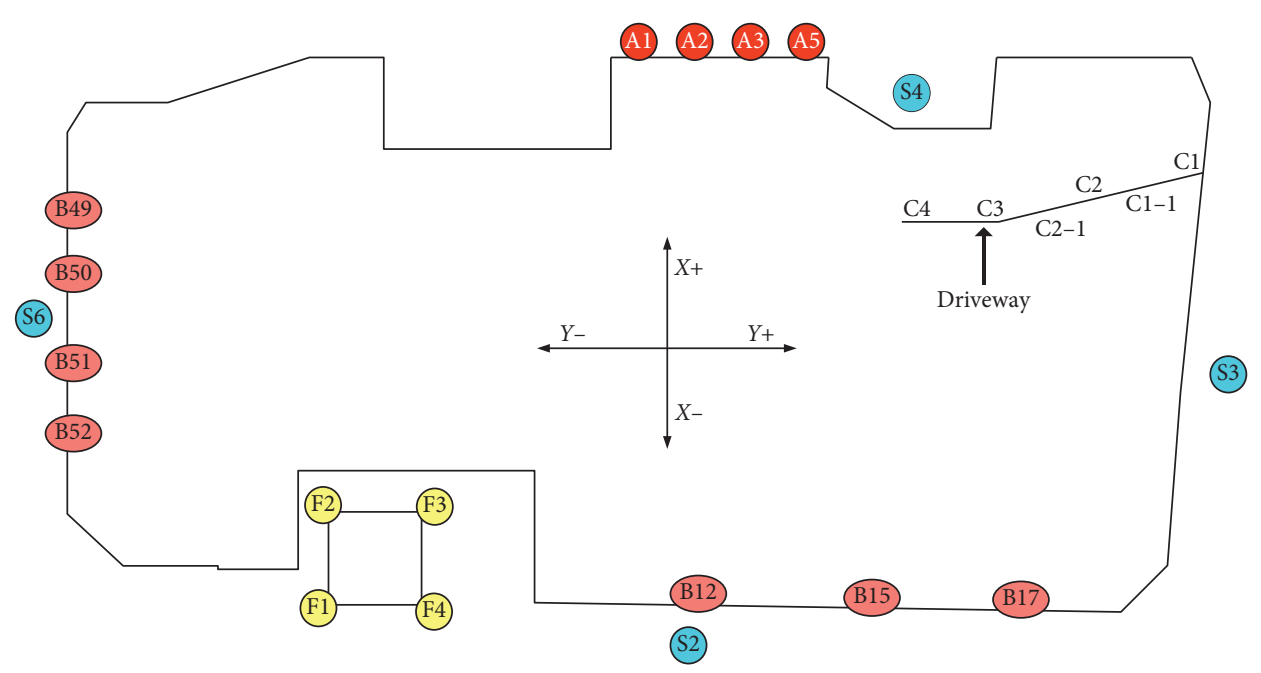

FIGURE 1: Layout of foundation pit monitoring points.

Figure 3(c). As can be seen from Figure 3(a), the settlement displacement of the crown beam and driveway in the foundation pit is roughly the same, both of which settle to a certain extent with the progress of soil excavation and eventually tend to be stable. The maximum settlement accumulation of the crown beam and driveway occurred at the monitoring point $\mathrm{C} 2$, which was $7.03 \mathrm{~mm}$, not reaching the alarm value $( \pm 20 \mathrm{~mm})$, which proved that the supporting system adopted in the foundation pit engineering played a good role in restraining the settlement of the soil in the foundation pit. Figure 3(b) shows that the settlement displacement curve of buildings around the foundation pit continues to decline after a period of stability ( $600 \mathrm{~d}-1000 \mathrm{~d}$ ) and does not reach a stable state again in the whole monitoring cycle. It can be seen from Figure 3(c) that the soil on the north side of the foundation pit has subsidence in the whole monitoring period. Although the ground subsidence observed at the monitoring points on the north side of the foundation pit (A1, A2, A3, and A5) and the surrounding buildings (F1, F2, F3, and F4) were all alarm values until the end of monitoring, the monitored settlement displacement curve could not reflect the maximum deformation value of the ground subsidence there. The same phenomenon is also mentioned in literature $[1,2]$. Therefore, it is suggested to extend the monitoring time of surface subsidence in these two places.

3.3. Stress of Anchor Cable. The anchor cable stress monitoring adopts the anchor cable dynamometer installed on the anchor cable [31-34], which is installed in the middle of each edge, the sun corner, and the section with complex geological conditions. Correspondent to the horizontal displacement curve of pile head, the monitoring data (M10, M15, M33, and M45) of the first layer of the anchor cable in different areas were selected for analysis to obtain the curve of the axial force of anchor cable in the first layer over time, as shown in Figure 4. As can be seen from Figure 4, in the whole monitoring cycle, the change rule of axial force of the first layer anchor cable with time in different areas is basically the same. With the excavation, the axial force of anchor cable decreases and finally becomes stable. The timehistory evolution curve of the anchor cable axial force has a good consistency with the horizontal displacement curve of the pile top. At the beginning of excavation, the anchor cable axial force curve has a large drop and then enters the period of shock decline. Finally, the anchor cable axial force curve tends to be stable with the completion of soil excavation. It is not difficult to find that corresponding to the horizontal displacement of each side of the foundation pit is similar, and the cumulative loss of axial force of the anchor cable of the first layer in different areas is also roughly the same, which indicates that the supporting system adopted in this project has played a better role in limiting the displacement of the soil.

3.4. Groundwater Level. The water level monitoring holes are arranged along the foundation pit and around the protected object $[35,36]$. The interval between the monitoring holes is $20 \mathrm{~m}-50 \mathrm{~m}$, and a total of water level monitoring holes are arranged. The bottom of the water level pipe is sealed to prevent sediment from entering the pipe. The bottom of the water level pipe flows $0.5-1 \mathrm{~m}$ to deposit a small amount of mud and sand brought by the water filter section. No holes shall be drilled in the area $2 \mathrm{~m}$ below the surface to ensure the sealing quality and the pores outside the pipe shall be blocked with cohesive soil to avoid the inflow of surface water into the pipe. The water level pipe is about $300 \mathrm{~mm}$ above the ground, and it is covered to prevent rainwater from entering. During the water level measurement, the side head is moved slowly downward. 


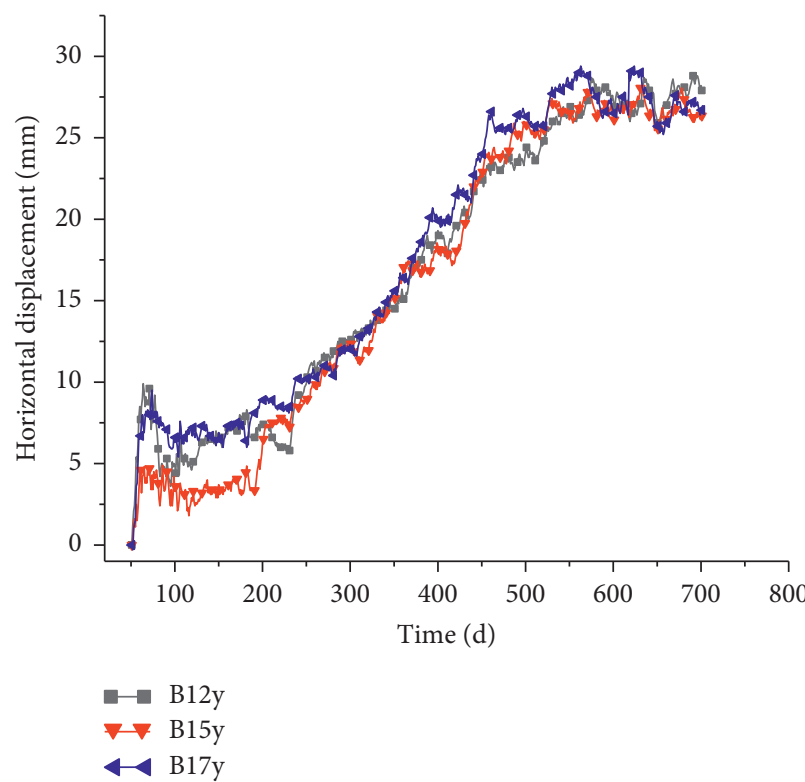

(a)

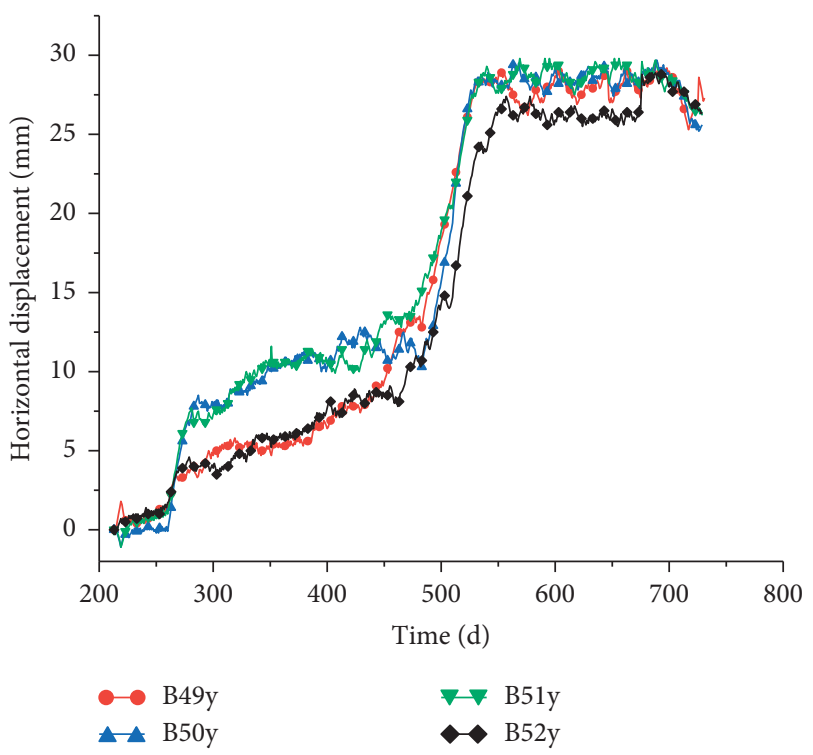

(b)

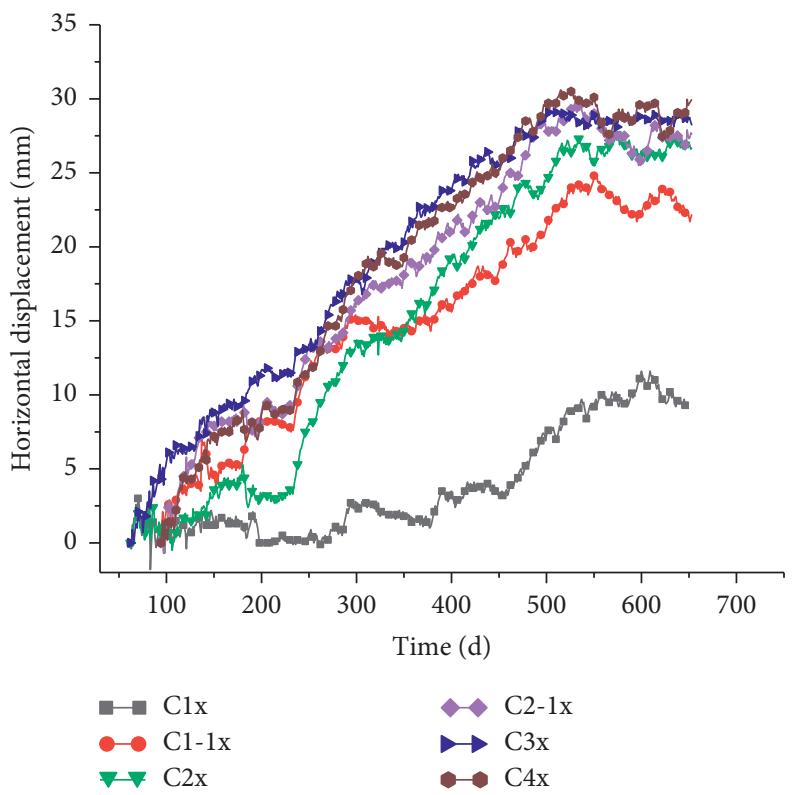

(c)

Figure 2: Horizontal displacement curve of crown beam and driveway in the foundation pit. (a) Horizontal displacement of the long side of the foundation pit. (b) Horizontal displacement of short edge of the foundation pit. (c) Horizontal displacement of the driveway.

When the side head touches the water surface, the receiving system sends out a signal, and the ground water level elevation can be obtained according to the reading of the steel ruler cable at the pipe opening. The groundwater level monitoring data (S2, S3, S4, and S6) at each side of the foundation pit were selected for analysis, and the timehistory variation curve of the groundwater level of the foundation pit was obtained, as shown in Figure 5. Figure 5 shows that there are great differences in the specific changes of the groundwater level at each side of the foundation pit. The water level in the south and east side of the foundation pit experienced a large drop in a short time and then quickly stabilized. The S4 data of the monitoring point on the north side of the foundation pit showed that the water 


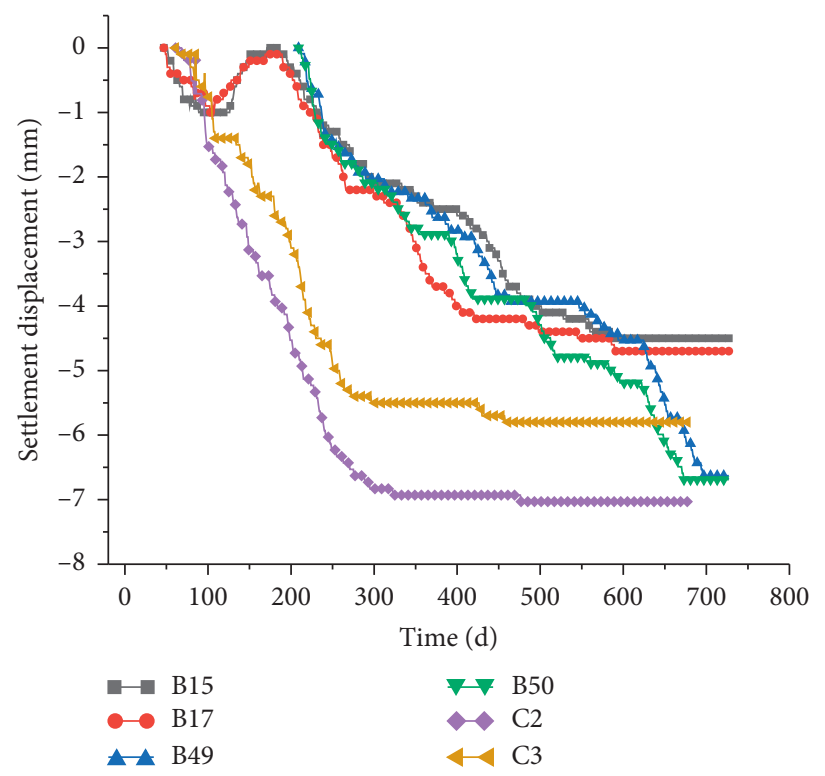

(a)

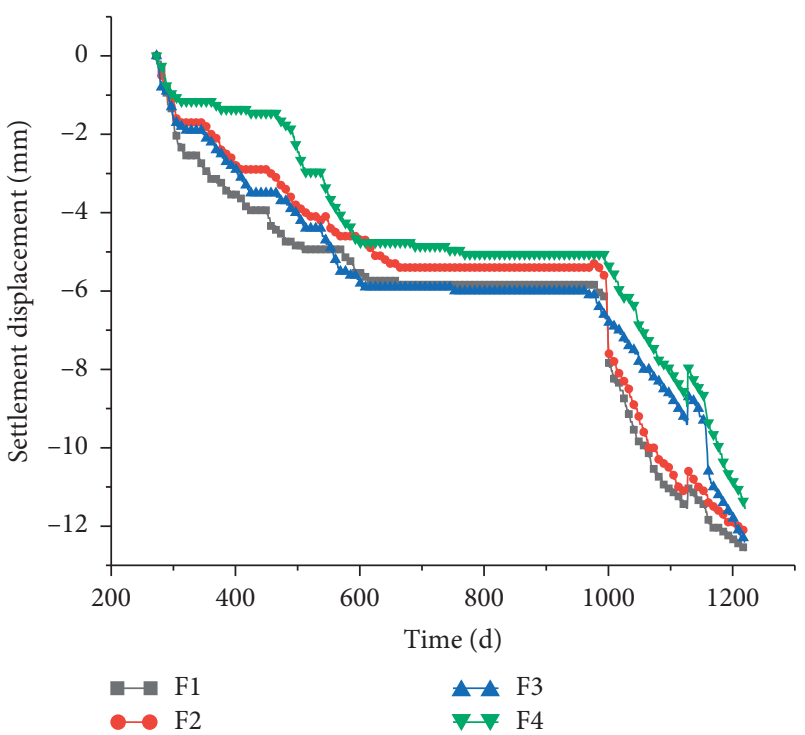

(b)

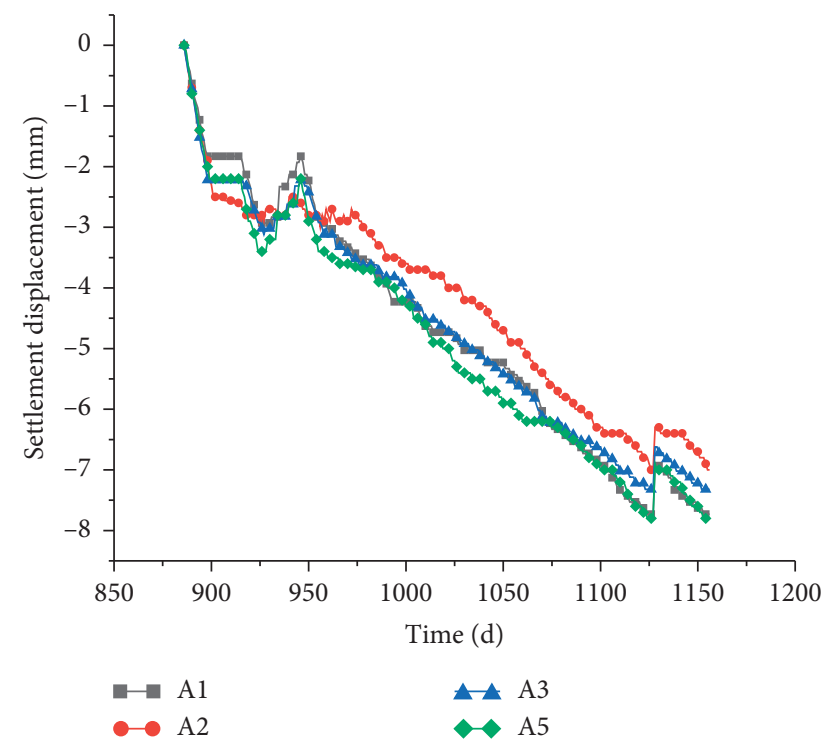

(c)

Figure 3: Settlement displacement curve of each area of the foundation pit. (a) Settlement displacement curve of the foundation pit crown beam and driveway. (b) Settlement displacement curve of buildings around the foundation pit. (c) Settlement displacement curve on the north side of foundation pit.

level changed little during the whole monitoring period. The groundwater level in the east of the foundation pit decreases first and then rises to the initial level and then tends to be stable. It is proved that the water stop curtain of double row jet grouting pile plays a good water retaining function in the foundation pit engineering. According to the data of four monitoring points, the groundwater level of S2 on the south side of the foundation pit fluctuates the most, up to $5.4 \mathrm{~m}$. The second is $\mathrm{S} 3$ on the east side of the foundation pit, and the change of the groundwater level is about $1.6 \mathrm{~m}$. Yadav et al. [1] also found that the change of the groundwater level in the foundation pit reached $4.5 \mathrm{~m}$ within dozens of days. This is mainly because the groundwater in the deep foundation pit project in this paper is abundant and fluctuates greatly, but it does not trigger the monitoring and alarm system. 


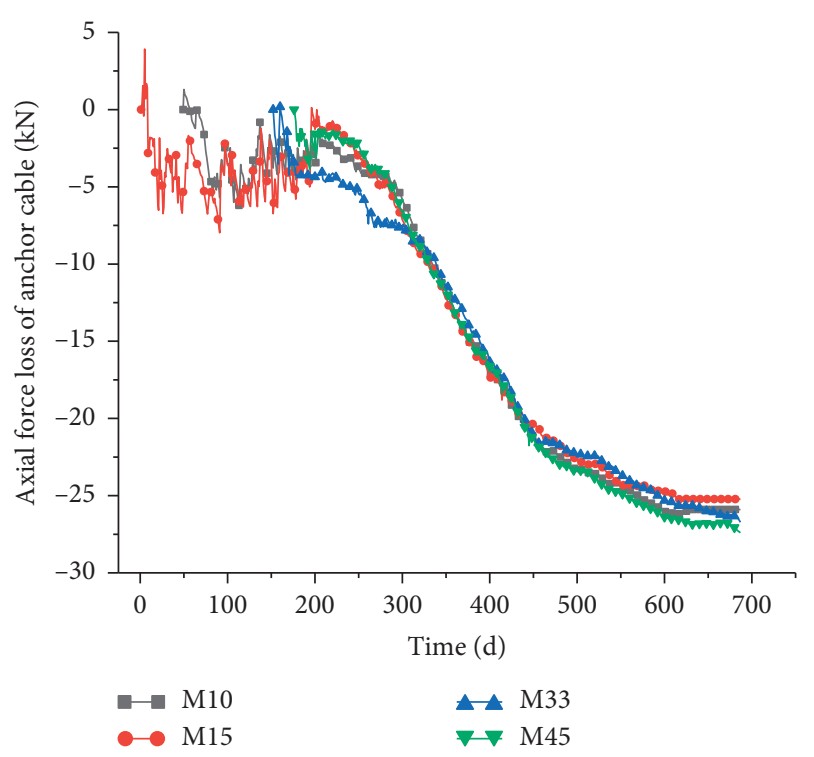

FIgURE 4: Time-history variation curve of axial force loss of the anchor cable.

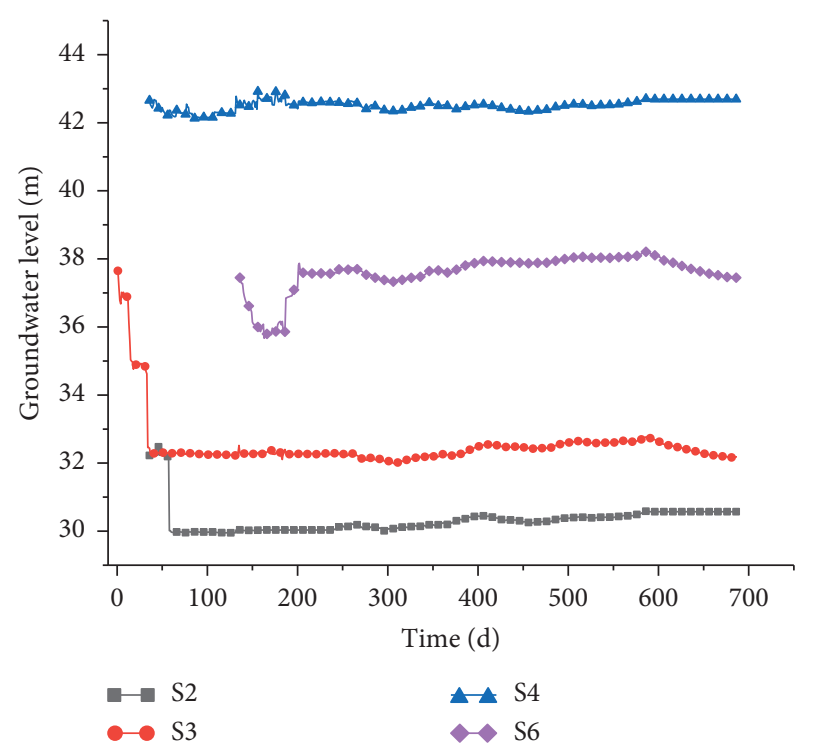

Figure 5: Time-history curve of the groundwater level.

\section{Conclusions}

(1) For super-large deep foundation pit engineering, the support system of double row jet grouting pile watersealing curtain + artificial hole-digging pile + prestressed anchor cable plays a good supporting role. In the whole monitoring period, the horizontal displacement of the crown beam and driveway of the foundation pit, the ground settlement in each area of the foundation pit, the axial force loss of the anchor cable, and the change of the underground water level do not reach the alarm value, which indicates that the design scheme of the pile-anchor supporting system used in the foundation pit is safe and reliable.
(2) With the excavation of the foundation pit, the crown beam and driveway of the foundation pit will move in the direction of the pit and eventually tend to be stable. The variation curve of the prestressed anchor cable of the first layer in each area of the foundation pit is in good consistency with the variation curve of the horizontal displacement time history. The variation trend of the groundwater level at each side of the foundation pit is different but tends to be stable in a short time.

(3) With the excavation of the soil, the settlement of the foundation pit and the surrounding area will occur to a certain extent. During the whole monitoring period, the cumulative settlement value of each area of the foundation pit is within the controllable range. However, the data of the newly added monitoring points on the north side of the foundation pit and the monitoring points of a surrounding building show that the surface settlement has not reached stability. Therefore, it is suggested to extend the monitoring time of settlement in the relevant areas.

\section{Data Availability}

The data used to support the findings of this study are available from the corresponding author upon reasonable request.

\section{Conflicts of Interest}

The authors declare that there are no conflicts of interest.

\section{References}

[1] S. K. Yadav, U. Amjad, and P. K. Basudhar, "Reinforcement effect on the static analysis of circular footing resting over winkler elastic foundation," Geotechnical \& Geological Engineering, vol. 38, pp. 1-17, 2018.

[2] Y. Wang, P. Guo, F. Dai, X. Li, Y. Zhao, and Y. Liu, "Behavior and modeling of fiber-reinforced clay under triaxial compression by combining the superposition method with the energy-based homogenization technique," International Journal of Geomechanics, vol. 18, no. 12, Article ID 04018172, 2018.

[3] T. Wood and M. Karstunen, "Modelling the creep of deep foundations in soft gothenburg clays," European Journal of Environmental and Civil Engineering, vol. 87, pp. 1-19, 2017.

[4] C. Panganayi, H. Ogata, K. Hattori, and T. Tom, "Interaction between engineered cementitious composites lining and foundation subsurface drain," Advances in Civil Engineering, vol. 2011, Article ID 280717, 9 pages, 2011.

[5] R. Yang, J. Huang, D. V. Griffiths, J. Li, and D. Sheng, "Importance of soil property sampling location in slope stability assessment," Canadian Geotechnical Journal, vol. 56, no. 3, pp. 335-346, 2019.

[6] D. W. M. Chan, T. O. Olawumi, and A. M. L. Ho, "Perceived benefits of and barriers to building information modelling (BIM) implementation in construction: the case of Hong Kong," Journal of Building Engineering, vol. 25, Article ID 100764, 2019. 
[7] B. Yuan, M. Sun, L. Xiong, Q. Luo, S. P. Pradhan, and H. Li, "Investigation of 3D deformation of transparent soil around a laterally loaded pile based on a hydraulic gradient model test," Journal of Building Engineering, vol. 28, Article ID 101024, 2020.

[8] B. Yuan, M. Sun, Y. Wang, L. Zhai, Q. Luo, and X. Zhang, "Full 3D displacement measuring system for 3D displacement field of soil around a laterally loaded pile in transparent soil," International Journal of Geomechanics, vol. 19, no. 5, Article ID 04019028, 2019.

[9] B. Yuan, K. Xu, Y. Wang, R. Chen, and Q. Luo, "Investigation of deflection of a laterally loaded pile and soil deformation using the PIV technique," International Journal of Geomechanics, vol. 17, no. 6, 2017.

[10] L. Luan, Y. Liu, and Y. Li, "Numerical simulation for the soilpile-structure interaction under seismic loading," Mathematical Problems in Engineering, vol. 2015, Article ID 959581, 7 pages, 2015.

[11] C. Chreties, L. Teixeira, and G. Simarro, "Pile group protection with riprap mattress," Advances in Civil Engineering, vol. 2012, Article ID 693506, 7 pages, 2012.

[12] N. Letizia, C. Iodice, and A. Mandolini, "A local design method for pile foundations," Advances in Civil Engineering, vol. 2018, Article ID 9486945, 14 pages, 2018.

[13] M. Mohammed, A. Sharafati, N. Al-Ansari, and Z. M. Yaseen, "Shallow foundation settlement quantification: application of hybridized adaptive neuro-fuzzy inference system model," Advances in Civil Engineering, vol. 2020, Article ID 7381617, 14 pages, 2020.

[14] M. -Y. Zhang, J. -X. Ma, S. -J. Yang, Y. -H. Wang, X. -Y. Bai, and S. -X. Sun, "Experimental study on bending moment of double-row steel pipe piles in foundation excavation," $A d$ vances in Civil Engineering, vol. 2020, Article ID 8882713, 8 pages, 2020.

[15] H. Lai, H. Zheng, R. Chen, Z. Kang, and Y. Liu, "Settlement behaviors of existing tunnel caused by obliquely under-crossing shield tunneling in close proximity with small intersection angle," Tunnelling and Underground Space Technology, vol. 97, Article ID 103258, 2020.

[16] A. Alam, N. Wang, G. Zhao, and A. Barkat, "Implication of radon monitoring for earthquake surveillance using statistical techniques: a case study of wenchuan earthquake," Geofluids, vol. 2020, Article ID 2429165, 14 pages, 2020.

[17] C. Zhang, C. Pu, R. Cao, T. Jiang, and G. Huang, "The stability and roof-support optimization of roadways passing through unfavorable geological bodies using advanced detection and monitoring methods, among others, in the Sanmenxia Bauxite Mine in China's Henan Province," Bulletin of Engineering Geology and the Environment, vol. 78, no. 7, pp. 5087-5099, 2019.

[18] M. Naderloo, M. Moosavi, and M. Ahmadi, "Using acoustic emission technique to monitor damage progress around joints in brittle materials," Theoretical and Applied Fracture Mechanics, vol. 104, Article ID 102368, 16 pages, 2019.

[19] Y. Chen, H. Lin, X. Ding, and S. Xie, "Scale effect of shear mechanical properties of non-penetrating horizontal rocklike joints," Environmental Earth Sciences, vol. 80, no. 5, p. 192, 2021.

[20] S. Xie, H. Lin, Y. Wang et al., "Nonlinear shear constitutive model for peak shear-type joints based on improved Harris damage function," Archives of Civil and Mechanical Engineering, vol. 20, no. 3, p. 95, 2020.

[21] T. Dezert, S. Palma Lopes, Y. Fargier, L. Saussaye, and P. Côte, "Data fusion of in situ geophysical and geotechnical information for levee characterization," Bulletin of Engineering Geology and the Environment, vol. 80, no. 6, pp. 5181-5197, 2021.

[22] C. Gokceoglu, S. Kocaman, H. A. Nefeslioglu, and A. O. Ok, "Use of multisensor and multitemporal geospatial datasets to extract the foundation characteristics of a large building: a case study," Bulletin of Engineering Geology and the Environment, vol. 80, no. 4, pp. 3251-3269, 2021.

[23] H. Lin, X. Zhang, R. Cao, and Z. Wen, "Improved nonlinear Burgers shear creep model based on the time-dependent shear strength for rock," Environmental Earth Sciences, vol. 79, no. 6, p. 149, 2020.

[24] M. O. Kluger, S. Kreiter, F. T. Stähler, M. Goodarzi, T. Stanski, and T. Mörz, "Cone penetration tests in dry and saturated Ticino sand," Bulletin of Engineering Geology and the Environment, vol. 80, no. 5, pp. 4079-4088, 2021.

[25] P. Rizzo, "Water and wastewater pipe nondestructive evaluation and health monitoring: a review," Advances in Civil Engineering, vol. 2010, Article ID 818597, 13 pages, 2010.

[26] Y. Chen, H. Lin, R. Cao, and C. Zhang, "Slope stability analysis considering different contributions of shear strength parameters," International Journal of Geomechanics, vol. 21, no. 3, Article ID 04020265, 2021.

[27] C. Zhu, K. Zhang, H. Cai et al., "Combined application of optical fibers and CRLD bolts to monitor deformation of a pitin-pit foundation," Advances in Civil Engineering, vol. 2019, Article ID 2572034, 16 pages, 2019.

[28] V. Bennett, T. Abdoun, M. Zeghal, A. Koelewijn, M. Barendse, and R. Dobry, "Real-time monitoring system and advanced characterization technique for civil infrastructure health monitoring," Advances in Civil Engineering, vol. 2011, Article ID 870383, 12 pages, 2011.

[29] C. Zhang, C. Wu, and P. Wang, "Seismic fragility analysis of bridge group pile foundations considering fluid-pile-soil interaction," Shock and Vibration, vol. 2020, Article ID 8838813, 17 pages, 2020.

[30] Y. Xie and S. Chi, "Optimization method of reducing the differential settlements of piled raft foundations based on pileto-pile interaction theory," Advances in Civil Engineering, vol. 2020, Article ID 1521876, 14 pages, 2020.

[31] M. Y. Koca, C. Kincal, A. T. Arslan, and H. R. Yilmaz, "Anchor application in Karatepe andesite rock slope, IzmirTürkiye," International Journal of Rock Mechanics and Mining Sciences, vol. 48, no. 2, pp. 245-258, 2011.

[32] H. Lin, P. Sun, Y. Chen, Y. Zhu, X. Fan, and Y. Zhao, "Analytical and experimental analysis of the shear strength of bolted saw-tooth joints," European Journal of Environmental and Civil Engineering, vol. 24, pp. 1-15, 2020.

[33] E. Komurlu and A. Kesimal, "Experimental study on usability of friction rockbolts with plastic bodies," International Journal of Geomechanics, vol. 17, 2017.

[34] M. Ranjbarnia, A. Fahimifar, and P. Oreste, "Practical method for the design of pretensioned fully grouted rockbolts in tunnels," International Journal of Geomechanics, vol. 16, no. 1, Article ID 04015012, 2016.

[35] D. Kuttah and H. Arvidsson, "Effect of groundwater table rising on the performance of a Swedish-designed gravel road," Transportation Geotechnics, vol. 11, pp. 82-96, 2017.

[36] M. Pirone, R. Papa, M. V. Nicotera, and G. Urciuoli, "In situ monitoring of the groundwater field in an unsaturated pyroclastic slope for slope stability evaluation," Landslides, vol. 12, no. 2, pp. 259-276, 2015. 